\title{
Forensic studies of dog attacks on humans: a focus on bite mark analysis
}

This article was published in the following Dove Press journal:

Research and Reports in Forensic Medical Science

12 October 2015

Number of times this article has been viewed

\author{
Gabriel M Fonseca' \\ Esther Mora ${ }^{2}$ \\ Joaquin Lucena ${ }^{3}$ \\ Mario Cantin ${ }^{4}$ \\ 'Faculty of Dentistry, Laboratory \\ of Forensic Dentistry, University \\ of La Frontera, Temuco, Chile; \\ ${ }^{2}$ Dental Sinai Hospital \& Research \\ Center, ${ }^{3}$ Forensic Pathology Service, \\ Institute of Legal Medicine, Seville, \\ Spain; ${ }^{4}$ Faculty of Dentistry, Doctoral \\ Program in Morphological Science, \\ Universidad La Frontera, Temuco, \\ Chile
}

\begin{abstract}
The interaction between domestic animals and humans has not been free of conflicts, and dog attacks represent a real problem, not only for the health consequences, but also for the possible criminal, and can affect the legal or financial outcomes. Dogs' teeth have particular features, and the resulting bite marks are a major point of forensic interest mainly in the absence of witnesses or in cases where postmortem dog interference can be misinterpreted. An appropriate forensic approach should include an exhaustive analysis of the scene, the victim, and the dog. Bite marks must be discriminated from other traumas, and the familiarity of the investigator with different patterns of animal behavior can be of great importance in the correct assessment of the offending specie. A scientific inclusion/exclusion of the dog involved is possible and also recommended because of the possible consequences for the owner of the animal. Since dog bite mark analysis should involve different forensic professionals such as pathologists, odontologists, veterinarians, biologists, and also police investigators, a review focused on this type of evidence from a multidisciplinary point of view is presented. Prevention and mitigating strategies focused on both breed-specific legislation and the legal responsibility of the owner for the dog's behavior are discussed.
\end{abstract}

Keywords: fatal dog attack, scavenging, bite mark, dog behavior, forensic pathology, forensic dentistry

\section{Introduction}

Domesticated animals, particularly dogs, have provided companionship, labor, recreation, and entertainment for humans. ${ }^{1}$ However, as the result of the most diverse causes, this interaction has not been free of conflicts. The alarming statistics reported around the world $^{2,3}$ have shown that dog attacks today represent a health hazard where prevention strategies have not always been successful. Most of the dogs involved in these events are known to the victim or belong to him. ${ }^{2-8} \mathrm{~A}$ bite mark is defined as a physical alteration in a medium caused by the contact of teeth. ${ }^{9}$ When a bite mark is caused by an animal, the following three patterns can be observed: nonfatal bite wounds, fatal bite wounds, and postmortem lacerations of the victim's body. ${ }^{2}$ This poses the major points and challenges of forensic interest; the nature and location of injuries and the final cause of death are not the only topics of attention. ${ }^{2,69}$ A careful assessment of wounds can reveal characteristic features of animal activity with typical patterns that may enable identification of the particular species of animal involved. ${ }^{10}$ Since dog attacks on humans represent a real health problem with obvious challenges for forensic investigation, a review focused on bite mark analysis from a multidisciplinary point of view is presented, and the current strategies for prevention and mitigation are discussed.
Correspondence: Gabriel M Fonsec Faculty of Dentistry, Laboratory of Forensic Dentistry, University of La Frontera, Avenida Francisco Salazar 0I I45, Edificio L, Temuco 48I I230, Chile Tel +56 452734005 Email gabriel.fonseca@ufrontera.cl 


\section{The carnivore, the canidae}

The taxonomic order Carnivora (not referring to feeding habits but to characteristic skull shape, jaws, and teeth among others distinguishing features) consists of $\sim 270$ extant species that include many of the world's top terrestrial predators, iconic wild animals, and man's favorite pets, including dogs and cats. Carnivora has been divided into two superfamilies, Caniformia (dog-like carnivores) and Feliformia (cat-like carnivores). Canidae (dogs and relatives) belongs to the infraorder Canoidea within the Caniformia superfamily. Dogs are still wolves beneath the skin; ${ }^{8}$ recent findings confirm that the $\operatorname{dog}$ (Canis lupus familiaris) was domesticated from the Eurasian wolf (Canis lupus lupus). ${ }^{11}$

Dogs have particular dental and maxillofacial features. Their dental formula is incisors $3 / 3$, canines $1 / 1$, premolars $4 / 4$, and molars $2 / 3$. The incisors are used for nibbling, producing small parallel furrows on bone. Following a space (largest in the maxilla), two long, pointed canines are positioned at the corners or the arch. They are long, slightly serrated and sharp, and they are used to stab and tear and produce puncture wounds. Behind them, there is a diastema followed by a small first premolar. The second, third, and fourth premolars are separated and become increasingly larger. The premolars are used to grasp the prey and will produce striations on the bone. The first molar is the largest molar, followed by progressively smaller molars. They have small cusps and are used for crushing. The fourth maxillary premolars and the first molar are referred usually as carnassials, and they are extremely sharp. Premolars and molars have three aligned cusps or tubercles forming a triangle during biting and interlock allowing grasping and lacerating. The upper teeth distal to the lower teeth allow the so-called scissor bite with which the animal can lock onto its prey. The bites produced by the upper teeth on one side of the limb would be different in appearance from those produced by the lower teeth on the opposite side. When the animal begins to shake its head, the skin and muscle of the bite victim can be seriously torn. The huge force the bite muscle complex can exhibit allows the dog to wrench and tear and cause considerable damage. . $^{2,4,6,8,9,12,13}$

Although there are reports in which many breeds of dogs have been involved in fatal or nearly fatal attacks on humans, the majority of cases involve pit bull-type dogs, Rottweilers, and German Shepherds, most of whom were unrestrained on their owner's holdings. ${ }^{1,2,6,13-15}$ The expression "pit bull-type" defines a group of breeds with special features and behavioral characteristics: a tendency to not to make intimidating gestures (growling and baring of teeth) prior to attacking, greater jaw pressures, a capacity to continue grinding their posterior teeth into tissues while holding on with the canines, and an aggressive personality in a relative larger size. All these features make them highly hazardous, especially to vulnerable people. ${ }^{4,13}$

\section{The dog is attacking}

Dogs incline to drag their preys down and then maul. A dog attempts to disable the victim by hitting at the limbs; once the subject has been down, the animal usually bites the throat, neck, or cranium, and if the attack continues, death will finally result from asphyxiation, exsanguination, or a fractured cranium and its complications. ${ }^{4,13,16}$ Unlike cats, dogs eat before the prey is dead if that is their intention. In fact, when a dog pack is involved, each member of the gang tears at the prey, fight over the parts, and eats the meat in a substantial quantity as quickly as possible. ${ }^{16}$ It is not uncommon for victims of dog attacks to be found naked, which may falsely suggest a rape rather than a dog mauling., ${ }^{2,17}$

Attacking incidents occur most frequently around the victim's home. Attacks by pet dogs usually cause injuries to the head and neck region, whereas stray dogs often bite the hands and legs; this is probably because people have different attitudes and behaviors with pets or with stray dogs. Children are frequently bitten in the head and neck area because these anatomic regions are of the same height as the dogs' mouth. ${ }^{2}$ In a defensive or anger bite, a dog may attempt to bite and let go showing superficial anterior tooth marks similarly to a human bite. In a predatory bite, a dog can clamp a large portion of tissue using posterior teeth and cause drag marks and lacerations by shaking and pulling. If the fastening is lost, a dog tries to thrust its head forward to seize more tissue, thus creating double or superimposed bites. ${ }^{9}$

Children are especially defenseless to mauls from domestic dogs for different motives. They are small and run quickly mimicking small prey, and they are usually unable to escape from a mauling dog. Children may inadvertently hurt or provoke the animal, and they are also weak to offer defense if a larger dog begins to maul. ${ }^{13}$ Tsokos et al refer that "the small size and plasticity of the infant head also means that a large dog may be able to fit a young child's cranium into its mouth, and to exert considerable crushing forces, with biting pressures of 200-400 pounds per square inch."13

When dog bites are nonfatal, the forensic investigation usually has no difficulty because the victim can describe the circumstances and identify the attacking animal. However, the absence of witnesses can cause more complex situations if the event has resulted in criminal or civil litigation. 
Attacks on disabled persons can be misinterpreted, leading to poor diagnoses and wrongful convictions. ${ }^{1,4}$ When lesions are fatal, they are usually located in the head and neck region causing death by means of asphyxia or hemorrhage. Septic shock, craniocerebral trauma, envenomation, anaphylaxis, or, less frequently, pulmonary embolism after cellulitis have been described as fatal consequences of a dog attack. ${ }^{2,6,13}$

From an ethological point of view (a focus on animal behavior under natural conditions), recognized functional responses and its behavioral parameters (capture rate and handling time) interact to determine the outcome and dynamics of the predator-prey interactions. ${ }^{18}$ The extent of the damage is related to the vulnerability of the victim: young children, the elderly, and disabled persons have the highest mortality rates because of their weakness, defenselessness, and smaller body sizes..$^{2-8,17}$ When dogs are part of a group, the "pack instinct" motivates to escalate the attack. ${ }^{7,16}$ The threat associated will be equivalent to the number and size of dogs and underlines the relevance of the victim's weakness. ${ }^{2,16,17}$ If the prey is taller, attacking canids try to immobilize it by hitting at the buttocks and limbs; once the victim has been brought down, dogs will attack him or her until he or she stops moving. Dogs produce important damage to the body, and the presence of "self-defense" injuries on forearms is not uncommon if the victim tried to keep away from the dog's mouth. ${ }^{2,13,17}$

It has been suggested that special attention should be paid to the patterns of behavior and the possible medical illnesses of the animals. ${ }^{2,6,8}$ The roles of hunger, prior predation and social facilitation of feeding, defense of territory, social interaction with people, environmental stimuli, estrus, and the number and size of dogs seem to be the primary causes of aggressive behavior. The flailing of limbs, rapid movements, high-pitched cries, and attempts at defense can increase the intensity of the attacks. Curiously, it is common for dogs to have an attitude of timidity and apprehension when researchers approach and examine them. ${ }^{5,7,13,17}$

Fonseca and Palacios mentioned that "while the cause of death may be readily apparent in cases of a fatal dog attack, an understanding of how and why the attack occurred requires a complete investigation and postmortem scavenging should be excluded". ${ }^{17}$ This particular pattern of behavior can occur whenever the body is accessible to animals. ${ }^{12}$ There is a preference for visible parts of the body, and self-defense injuries are absent if the victim died from other causes. ${ }^{13,17}$ The following three main consequences may be linked to scavenging: the lesions can mimic or cover antemortem injuries, make impossible the identification of the victim, and modify substantially the scene. ${ }^{12}$

\section{Challenges in forensic investigation}

Fatal dog attacks have been sporadically reported, and deaths usually result from unwitnessed attacks. ${ }^{13}$ Animal interferences can happen before and/or after the death of the victim, creating artifacts and difficulties in diagnosis during the forensic examination. ${ }^{19}$ Since introducing the dog bite mark evidence in court will require the skills of different experts in the forensic sciences, ${ }^{8}$ the different steps and procedures proposed in the literature are reviewed.

\section{General procedures}

The investigator must be aware of all pertinent legal terms about the examination of the scene, the victim, and the dog. All the evidence must be stored, and all actions must be documented. All the wounds (especially the puncture wounds) must be photographed and swabbed with canine-specific kits whenever possible. Collection of biological samples from wounds is recommended. In some cases, puncture wounds can be excised. ${ }^{8}$

\section{The scene}

A forensic approach to a suspected fatal dog attack should include not only the detailed exploration of the victim and the dog but also the appropriate assessment of the scene. Four stages have been recommended: 1) to obtain the information about the circumstances, witnesses, ages of victims, dog breed, etc; 2) to look for footprints, environmental conditions, position of the corpse, etc; 3 ) to collect trace evidence, blood samples, etc; and 4) to document with photographs, sketches, diagrams, etc. ${ }^{2}$ Although the most common situation is that certain experts do not have access to the scene or that they may be able to work using only photographs or the autopsy report, information of environmental and ecological features surrounding the scene may assist in its evaluation. The participation of all forensic investigators in all procedures could strengthen the trace recovery rates thus avoiding mistaken opinions. ${ }^{13,17,20}$

\section{Diagnosis of the wounds}

It is not a minor problem to discriminate bite marks from other traumas. ${ }^{19}$ Souviron $^{1}$ refers to an interesting case in which the wounds of a 7-year-old girl who was found dead and mutilated were misdiagnosed as stab wounds created by knives and/or scissors. The mother was charged with second-degree murder 11 days later and her other children 
were taken into custody (she was single). Although a Pit Bull Terrier was found at the time of death in the victim's house, and there was physical evidence of its involvement in the death, the mother spent almost 4 years awaiting trial for an inexistent murder, suffered over the death of her daughter, and lost custody of the other children. The evidence was not preserved, the appropriate experts were not asked for a timely evaluation, and finally, the prosecutor's office and experts were sued for malicious prosecution, false imprisonment, and gross negligence. ${ }^{1}$

\section{Diagnosis of the species involved}

The domestic dog accounts for the majority of deaths caused by animal attacks, but a variety of animals can leave similar patterns of damage. Souviron refers to a case involving a deceased 5-year-old girl found in a backyard adjoining a lake. Even though family members claimed that an alligator attacked the child, the forensic odontologist confirmed the primary diagnosis: the three family pit bulls mauled and killed her. ${ }^{1}$ Even though most fatal animal attacks are caused by large animals where the size and power of that animal simply overpower the individual, ${ }^{20}$ an exhaustive analysis of the scene, feces, hair, footprints, and claw marks is always recommended; the collection of biological samples from the wound margins can allow the confirmation of the species involved through species diagnostic markers. ${ }^{10,17,21-23}$ The location of the damage along the body and the familiarity of the pathologist with different patterns of animal behavior can be of paramount importance in the correct assessment of the offending animal. ${ }^{19,24}$ At this point, outdoor and indoor interferences have specific considerations of which to be aware. $^{12}$

If animal predation happens outdoors, the environmental status, meteorological conditions, local fauna, seasonal and diurnal variations, and an animal's feeding and behavior patterns are important issues to be explored. ${ }^{19}$ In a case of a 65-year-old man found dead with severe and unusual injuries, Kiuchi et al identified six different species as the offending animals. ${ }^{22}$ Even though dogs are the primary scavengers in certain outdoors contexts, ${ }^{21}$ they were excluded because of the absence of specific patterns of damage. ${ }^{22}$ Studies of dog behavior suggest they scavenge remains when they are nearly fresh and soft tissue reduction can be quick (Figure 1). Furthermore, the sequence of consumption and disarticulation of human bodies is relatively constant and recognized: feeding usually begins at the face and neck and then moves to the thorax. The upper extremities are then disarticulated from the trunk followed by the lower extremities. Finally, the

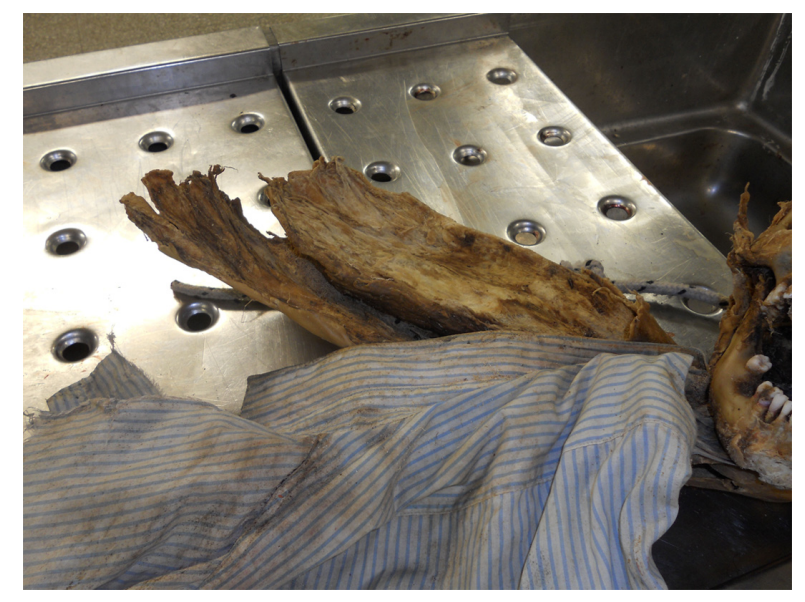

Figure I Outdoors scavenging by dogs of a dead-by-hanging male suicide. Notes: The age of the unidentified victim was estimated to be in the 55-65-year range. The dogs stretched and ripped the suspended victim, tightening the rope and producing a tourniquet effect. Finally, the victim was dismembered and scattered. Note the scalloped borders of the stretched skin representing the bite action of the dogs.

trunk is disarticulated and consumed. ${ }^{19,21}$ Coyotes, wolves, and domestic dogs are known to disarticulate body parts and scatter them over a wide area. ${ }^{21,25}$

In contrast to the outdoor context, the indoor interference is usually caused only by carnivores and rodents. The parallel cutaneous lacerations on the margins of damaged skin and the presence of feces in the vicinity of the deceased's head are distinctive of rodent activity. In cases of carnivore interference, the wound margin of injuries appears less regular and usually rounded, with scratch-type abrasions resulting by the action of claws. A careful look for potential footprints in bloodstains will allow for the detection of evidence of pets living free in the house or wild animals having possible access to the scene. ${ }^{12,13}$ Although domestic dogs do not feed on a corpse usually, they could be motivated by hunger to consume cadavers if they have no food available. ${ }^{12}$ Steadman and Worne reported in 2007 an interesting case in which a 54-year-old woman, who lived alone in her residence, was nearly completely consumed by her two domestic dogs (a Chow and a Labrador mix). All human biological evidence, including a mass of gray human head hair, a calvarium, and small fragments of long bones, were found in the main walkway of the living room between the bedroom and bathroom, and a considerable amount of animal feces covered the floors. The animals were confined for $\sim 4$ weeks and all their food had been consumed. They exhibited overall good health. ${ }^{25}$

\section{Cause and manner of death}

Death from dog attacks may be caused directly or indirectly by blunt and sharp trauma, crushing, envenomation, anaphylaxis, or sepsis. ${ }^{26,27}$ This wide variety of mechanisms can lead to 
problems of diagnosis if the forensic pathologist is not aware of all the details of the case. Blunt trauma from mauling or even paw marks (when the dog tries to rouse its owner) can be misinterpreted as the result of human activity. ${ }^{24,26}$ On the other hand, perpetrators have sometimes attempted to disguise homicides by feeding the remains of victims to animals. ${ }^{26}$ Moreover, postmortem injuries from animals are usually completely incidental to the cause and manner of death. ${ }^{26} \mathrm{~A}$ fatal attack is typically repetitive, with uninhibited bites to the neck and devastating injuries to the blood vessels, the spinal cord, and to the cranium. ${ }^{6}$ Antemortem dog attacks may produce similar injuries to those arising from postmortem feeding, and a meticulous analysis of the vitality of the injuries must be performed when necessary. ${ }^{26}$

Dogs are well known for their scavenging activities; this action invariably results in serious damage to the victim's body and may lead to a misdiagnosis of a brutal killing. Feeding often begins on the head and neck and the loss of tissue along with the consumption of the thyroid cartilage and hyoid bone can make the diagnosis of strangulation, among other causes of death impossible. The scattering of the clothes and removal of the genitals/genital regions of both men and women can raise the suspicion of sexual assault. Pets can bite their owners with the intention of waking them up and can cause injuries at the moment of death. ${ }^{1,19,28,29}$ Bite wounds inflicted after death like all such wounds do not usually bleed to any great extent. Consequently, the surrounding bloodstains would be distinct from the spatter emanating from a living person. ${ }^{28}$ A common situation of dog scavenging in indoor interferences is presented in Diogenes syndrome. The forensic evaluation of these death cases is often difficult because of the state of disrepair of the victim's house and the frequent presence of pet dogs (Figure 2). They are known to strip skin and tissues from the face (complicating identification) and to consume the thoracic organs making the determination of the cause of death difficult. ${ }^{19,29}$ The evaluators may have great difficulties in evaluating underlying alcoholism or significant illnesses that may have resulted in falls with bruising. ${ }^{26}$

Taphonomic changes induced by animal activity are very common, especially in outdoor contexts where the fauna is abundant. When only "dry bones" survive, the circumstances and manner of death might be obliterated by postmortem processes; animal activity on cadavers plays a major destructive role due to the tendency of animals to dismember the body as well as damage the tissues. ${ }^{24}$ Byard mentioned that injuries caused by animals during life may be nearly undetectable but completely relevant, and postmortem

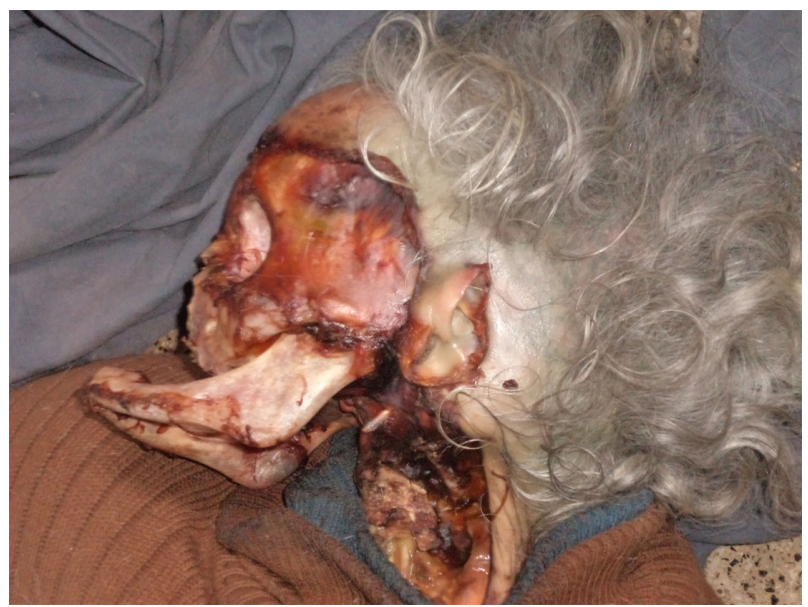

Figure 2 Postmortem, near total skeletization of the exposed face and neck of an 83-year-old woman who died of ischemic heart disease. The injuries were caused by two mixed-breed dogs.

Notes: The extreme squalor of the victim's house (with marked odor and piles of garbage) was indicative of Diogenes syndrome. Death had occurred several days before the body was found. The floors were covered with dog feces, and there was no available dog food. The public prosecutor's office ordered the euthanasia of both animals to prevent the recurrence of this feeding behavior. Image courtesy of Monica Hernandez, MD, Municipal Emergency Hospital of Cordoba, Argentina.

damage can significantly impair the pathological assessment of bodies. ${ }^{26}$ Several authors recommend an adequate training in forensic pathology acquiring familiarity with the types of artifacts that may be introduced by animal activity. ${ }^{19,26}$

\section{Analysis of wounds}

Autopsy of victims often reveals particular signs that relate directly to the dog's teeth and pattern of attack, with particular wounds and tissue avulsion. ${ }^{13}$ The injuries are

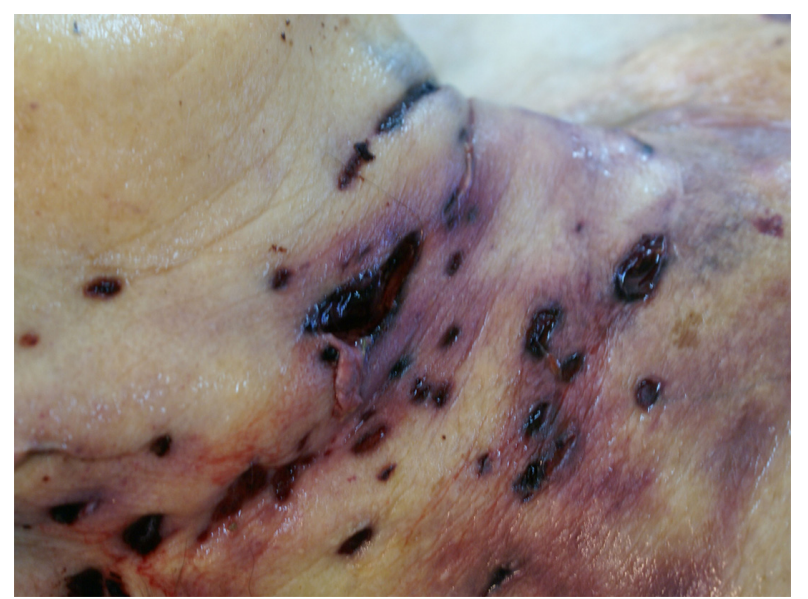

Figure 3 Multiple bite marks on the neck of an 85-year-old woman in a fatal pit bull attack.

Notes: The daughter of the victim indicated that the dog was provoked previously by the victim. Death was attributed to exsanguination due to the neck blood vessels' laceration subsequent to the dog bite. Note the " $\mathrm{V}$ "-shaped holes with irregular and wrinkled borders. Image courtesy of David Dib, MD, Institute of Forensic Medicine, and of the Laboratory of Forensic Dentistry, Cordoba, Argentina. 
represented by particular punctiform "V"-shaped holes and lesions presenting irregular and furrowed borders (Figure 3 ). The abovementioned typical "hole-and-a-tear" is a puncture wound (the round hole) produced by the canine tooth of either the maxilla or mandible on one side, which serves as an anchorage point, followed by shaking of the head creating tears enhanced by the cadaver's body weight. Wounds are licked in many cases and may take on a very bright and polished aspect. ${ }^{12,13}$ This pattern is accompanied by skin abrasions and superficial linear abrasions arranged parallel corresponding to claw marks, and usually present in the contour of the bite. ${ }^{13,16,17}$ There is a paucity of literature on the individualization of dog bite marks, discriminating bite marks from claw marks and their procedures. ${ }^{8}$ Bite wounds sometimes indicate characteristic tooth marks, whereas claw scratches can indicate paw size. These may enable not only the identification of the species responsible but also the individual animal. The latter is particularly the case where the person dies indoors or in an enclosed space in which the suspect animal is also confined. ${ }^{28}$

An unusual concentration of severe injuries to the head and neck region is typically reported in the literature, ${ }^{2,4,8,13}$ the bite mark pattern may vary considerably in shape and size depending on the bite mark recipient's head and neck movement, the animal's dentition, and its head movements. Cranium fragmentation may be found but decapitation is highly unusual. Neck wounds are usually slanted perpendicularly to the neck and positioned in an anteroposterior direction. Bites to the forearms are also common as the limbs are raised in an attempt to protect the face. Since the back is a relatively flat surface, the animal cannot open its jaw sufficiently wide to contact the canines with the skin. The bite mark pattern is considerably different from those on the limbs, the neck, and the cranium. These patterns allow the discrimination with bites of other species, which are not accompanied by shaking nor by the usage of canines, and with stab wounds caused by sharp weapons. ${ }^{2,4,8,13}$ Animal hair is occasionally found inside the wound. ${ }^{30}$ In cases with numerous wounds to the face, it has been recommended to take a cranial X-ray to check for bone fractures and the presence of foreign bodies. ${ }^{23}$

Canids leave typical postmortem damage patterns on the bones, characterized by rounded punctures, peg-like penetrating injuries, and shallow scratches. Severe damage caused by gnawing of the softer bony parts (proximal epiphyses) is frequently detected. ${ }^{24}$ Puncture marks are usually found in thin bones such as the scapula and are caused by the canines and/or carnassial teeth penetrating through the full thickness of the bone. The size, shape, and distribution of the puncture marks can give an indication of the size of animal that inflicted them. Pits are indentations that are inflicted by any of the teeth when grasping onto bone, whereas score marks result when the teeth are dragged along the surface of the bone. Furrows are deep channel-like grooves found along the length of the long bones such as the femur and are caused by the molars and premolars. When a dog spends a long time in chewing a bone, it turns it over and over resulting in a mass of grooves and pits from which it is difficult to discern individual tooth marks. ${ }^{12,25,28}$ Tokdemir et al stated that "the impact of animal intervention on the establishment of the time of death should be calculated by taking all adverse conditions into consideration including rate of the decomposition process of the corpse, and the presence of bugs and larvae around the dead body". ${ }^{19}$

\section{Investigation of the dog}

Given that any of the suspected dogs found at the scene could be involved, all of them should be examined whenever possible. ${ }^{8}$ Veterinary assistance will be necessary to examine for illness, estrus, or evidence of recent pregnancy. ${ }^{13}$ Detailed pictures and body schemas of the dogs as well as photographs of neck braces, scars, and evidence of prior veterinary treatment are useful to identify a potential dog and its owner. If the identity is known, past behavioral patterns or possibly training for attack must be explored., ${ }^{2,1328}$ Scarring or healing injuries may advise prior fighting of the animal..$^{13}$ It is important to collect any evidence belonging to the victim found on the animal: hair, blood, and cloth fibers. Urine samples, fecal matter, and contents of the animal's mouth and stomach must be examined, and nuclear and mitochondrial DNA examination of biological traces belonging to the animal located on the cadaver and associated clothes must be made whenever possible. ${ }^{2,13,19}$ Toxicological evaluation of fluids and tissues may be useful to evaluate any drugs such as excitants or steroids that may have led to deviant behavior. ${ }^{13}$ DNA analysis of blood and hairs has proved useful in linking dogs to the scene or victim; ${ }^{2}$ Brauner et $\mathrm{al}^{31}$ reported the case of a 10-month-old Neapolitan mastiff dog (Mastino napoletano) implicated in the mauling of a 6-year-old girl based on the reports of eyewitnesses. The owners of the dog stated that there were other dogs in the area similar to theirs and claimed that it was one of those that had injured the girl. Short tandem repeat DNA finally exculpated the animal because the blood on its coat did not belong to the victim. ${ }^{31}$ Even though the literature recommends the euthanasia of the animal, this procedure is justified only if brain samples are taken. The animal can be anesthetized for all the 
examinations, and the use of emetics may induce vomiting to examine the stomach content. ${ }^{8}$ The presence of commercial dog food may signify that the dog was a domestic pet and was not hungry, or wild food may signify a stray dog. ${ }^{13}$ The intact nature of some fragments of the victim's skin can denote the dogs' inclinations to not entirely chew food prior to swallowing. ${ }^{13}$ Since clothing fibers, rings and other jewelry (especially gold), bone fragments, and even whole teeth may be found in the dog's feces, radiographic examination is also recommended. ${ }^{10,28}$

Reproductions and casts of dogs' teeth and claws are recommended (Figure 4). If the dogs are alive, anesthesia should be used for this procedure. ${ }^{8}$ Bernitz et $\mathrm{al}^{8}$ explained that claw marks should be discriminated against in the bite marks. The claw pattern of the majority of dogs should be interpreted according to their anatomy of the forepaws: they are symmetrical, with longest digits 3 and 4, and absence of the digit 1 . The claw marks on the skin of the victim will be reflection both length and sharpness of the dog claws, and they will be affected by the surfaces walked by the dog, its size, and its breed. ${ }^{8}$

\section{The odontological bite mark analysis}

Odontological analysis of bite marks may provide conclusive evidence in identifying a particular animal.,31 While in the presence of multiple animal bites, it is difficult to apply a bite mark protocol that would record every wound individually, take impressions, and remove all of the affected tissue, ${ }^{1}$ the guidelines provided by the American Board of Forensic Odontology (http://www.abfo.org) for human bite

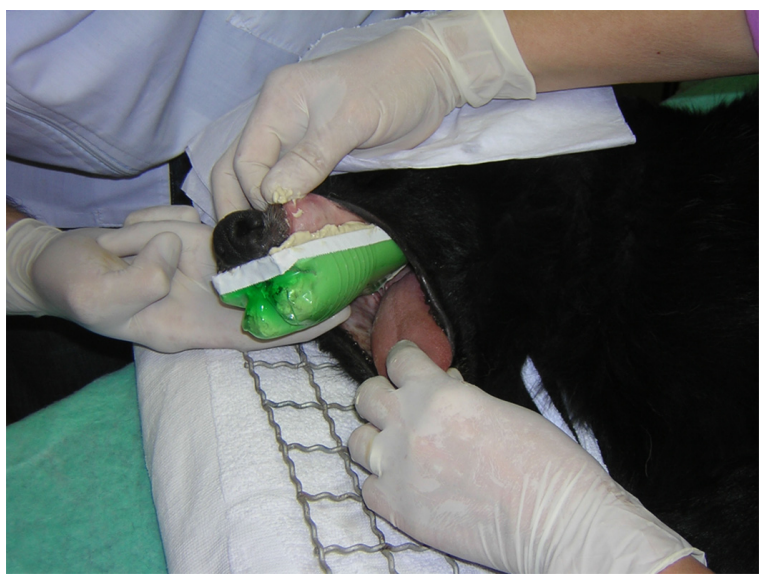

Figure 4 Experimental model designed for taking impressions of the dog's teeth by using an ad hoc recipient device (an adapted half bottle of plastic) and alginate. Notes: The procedure must be performed under general anesthesia in the case of living dogs. Image courtesy of forensic veterinary Noemi Friedrich, BVSc, and of the Laboratory of Forensic Dentistry, Cordoba, Argentina. mark analysis may be useful in the implementation of the photographic protocol and in the improvement of the quality of the expertise, resulting in more strong dog identification. ${ }^{16}$ Souviron recommends taking black-and-white, color, or alternate light photographs and video documentation. Selective tissue impression, excision, and preservation and direct tissue comparison are also recommended under certain circumstances. ${ }^{1}$

Bernitz et $\mathrm{al}^{8}$ defined the pattern association of dog bite marks/tooth marks as "the three-dimensional analysis and the comparison of the dental arch forms, arch relationships, and individual tooth features within the described canine dental arches". ${ }^{8}$ The bite mark is compared with dog maxillary and mandibular arch in shape, teeth position, and/or individual dental features. Obvious patterns, such as canine puncture traces, spaces between teeth, or abnormally positioned teeth, may allow a more reliable match with the bite mark. The interincisal and intercanine distances can discriminate the offending dogs if there are many suspected animals involved. ${ }^{3,8}$ The incisors may not produce markings, but the presence of six incisors of an arch mark excludes a human bite. Premolars and molar markings are also common since the dog's jaw can open widely. 4,9

Even though in considering that there are logical distortions of the soft tissues, the more stable patterns of the bite mark should be measured as a quality control of the procedure. Small dogs and larger dogs can be discriminated according to the intercanine distance. ${ }^{8}$ In cases of only bone remains with deep bites, the most accurate point to measure is the mesial bone height. ${ }^{32}$ The inclusion of a metric reference in the photographs will allow metric evaluations and calibrations by using an appropriate software. ${ }^{3,8}$ Bernitz et al suggest to avoid the problem posed by the length of the canines in the match of the dog's teeth with the cast of the bite mark, by lengthening and shortening their indentations in both duplicate models of the bite to correspond them when analysis is performed. As a result, the dog's incisors can be matched to the indentations on the plaster cast, representing a dynamic pattern of biting. ${ }^{8}$

Santoro et $\mathrm{al}^{16}$ reported a case of a 45 -year-old man found dead on the ground of an abandoned military base with signs that he had been dragged. He presented a wide wound in the face, especially on the left side including the neck. The wound's edges revealed many small, parallel, and partially curved superficial notch marks suggestive of bite wounds. The presence of blood at the scene and traces of subcutaneous bleeding suggested that the victim was alive when he was mauled to death. The cause of death was attributed to internal 
hemorrhage as a consequence of multiple fractures and external hemorrhage. The majority of bite marks were photographed and excised. The samples were fixed and stored. A pack of five dogs (four of them mixed breeds of German Shepherd and a Labrador mix) was known to demonstrate aggressive behavior and to have lived in the neighborhood. They were captured, anesthetized, and photographed, and then dental impressions of each dog were taken. The animals were not euthanized. Intercanine and interincisal extents on each cast were registered by using a digital caliper. After that, a comparison between the bite marks of the cutaneous samples and the dental casts was made. Positive concordances were made for three of the five dogs, probably the more active participants in the attack. The other two dogs had missing or worn teeth. ${ }^{16}$

In a similar case, Pomara et al reported the fatal dog pack attack of an 83-year-old woman found unconscious outside her farm where she lived with 27 dogs. ${ }^{6}$ The victim was unsuccessfully treated at the emergency department in the nearest hospital. Exsanguination due to brachial artery laceration subsequent to multiple dog bites was indicated as the main cause of death. Wide tears of the scalp and several tooth puncture wounds were detected on the neck and the whole body. The injuries were photographed, and the distances between pairs of punctures were measured. They were related to different dogs' teeth and to the pattern of mauling with punctures and lacerations (canines) and tissue avulsion (incisors). After that, samples of the best reproduced bite marks were excised by using a rigid ring (to minimize shrinkage), collected, and fixed in 10\% formalin. In association with a veterinary doctor, all the dogs were investigated (24 Cane Corso, 1 Dalmatian, and 2 German Shepherds). Metric records of all canine jaws and descriptions of dental patterns were recorded and compared with the wound samples; seven dogs were convincingly suspected to be responsible for the mauling. To identify the responsible dogs among the seven, a dental cast of each dog was prepared and superimposed on the victim's wound samples collected at autopsy. The jaws of the three suspected dogs could be clearly matched to the bite marks. The son of the victim indicated that the three responsible dogs were his own, and he was condemned for manslaughter. ${ }^{6}$

Is important to note that the odontologist does not usually visit the crime scene or even the mortuary, and he or she must work only from photographs or the autopsy report. ${ }^{1,17}$ A photograph is a static representation of a dynamic action, and it is not the way an animal bite looks like in reality. Murmann et al underlined that animal bites, especially that of dogs and carnivorous wildlife, can produce multiple deep, streaked lacerations requiring a considerable force, and resulting in the loss of tissue or avulsions. ${ }^{32}$ Conventional techniques to analyze and/or match these patterns (acetate sheeting for example) can be used but the resulting visual model will not represent the real dynamic of the bite mark. ${ }^{8}$ It has been emphasized that quality and quantity of the material must be sufficient and convincing to defend a positive match. Dog bite marks usually are distorted, and the lack of quality to individualize features can lead to over interpretations of marks. ${ }^{8}$ Only when deformations are minimal, testing the match using affine transformations can be obtained by importing pictures of both suspected dog's teeth and the bite mark into the open software GeoGebra as reported by Stols and Bernitz. ${ }^{33}$ Small amounts of warping, shrinkage, and distortion will not modify the relationships of characteristics within a bite mark. ${ }^{33}$ However, the distortions in dog bite marks are usually nonuniform and beyond the resolution power of affine transformations because of the deep stabbing of the canines and the only superficial penetration originated by the incisors. Bernitz et al believes that this great distortion can be adjusted only by a pattern association analysis; in fact, the physical matching of the dog's teeth to a reproduction of the bite mark can lead to this purpose as a $3 \mathrm{D}$ analysis. The authors mentioned that it is fundamental that appropriate standards must be followed from the beginning, and a computer-generated 3D analysis does not lead to a higher degree of positiveness in determined cases. Only if there are multiple points of similarity with no unjustifiable inconsistencies between the dentition of the dog and the bite mark, the conclusion of a match with a high degree of probability can be arrived. ${ }^{8}$

\section{Discussion}

Souviron is emphatic when he stated, "consultation with veterinarians, wildlife officers, forensic pathologists, odontologists, and anthropologists might prevent, reduce or correct misinterpretation of animal bites. A team approach provides the best opportunity for thorough documentation of circumstance, scene analysis, and proper photographic documentation". ${ }^{1}$ In dog bite cases, the court may ask an expert to identify which specific animal caused the wounds or the fatal bite to hold responsible the proprietor of the animal. ${ }^{8}$ Bite mark analysis is a delicate commission, and well-qualified experts have differing opinions about the interpretation and use of this type of evidence. ${ }^{2,4}$ The forensic evaluation of a dog attack needs an integrated approach by a forensic pathologist with a forensic veterinary involving a review of the circumstances of death, 
death scene examination, and autopsy examination of the corpse. When bite marks are found, the skills of a forensic odontologist are advised. Also a forensic biologist can provide additional data on sources of attacks or scavenging that can be used to evaluate such incidents. ${ }^{1,6,8,13}$ In a case reported by Fonseca and Palacios, a forensic odontologist and a carnivore biologist revealed that the injuries in a fatal attack were consistent with a pack dog attack (Figure 5). Both experts clarified that "although the evidence in this particular case was sufficiently categorical to establish the animal species that produced the fatal attack, the poorly processed scene and the lack of complete information of the autopsy were completely irregular and could lead to wrong conclusions" (the preliminary hypothesis considered that the attack was produced by a cougar or a big dog). ${ }^{17}$

\section{The vitality of the wounds}

As previously mentioned, one of the crucial points to establish the type of canine intervention is to determine the vitality of the wounds. ${ }^{26}$ Deaths resulting from natural disease, accidents, homicides, or suicides may not be detected for some time during which animal intervention sometimes can be misinterpreted, creating different scenarios. Antemortem injuries may also provide alternative access points for animals. This may result in the consumption of gunshot wounds (with or without projectiles) and stab wounds, making postmortem assessment of lethal wounds difficult. ${ }^{10,23,26,34}$ To make the picture even more complex, in certain fatal dog attacks, injuries

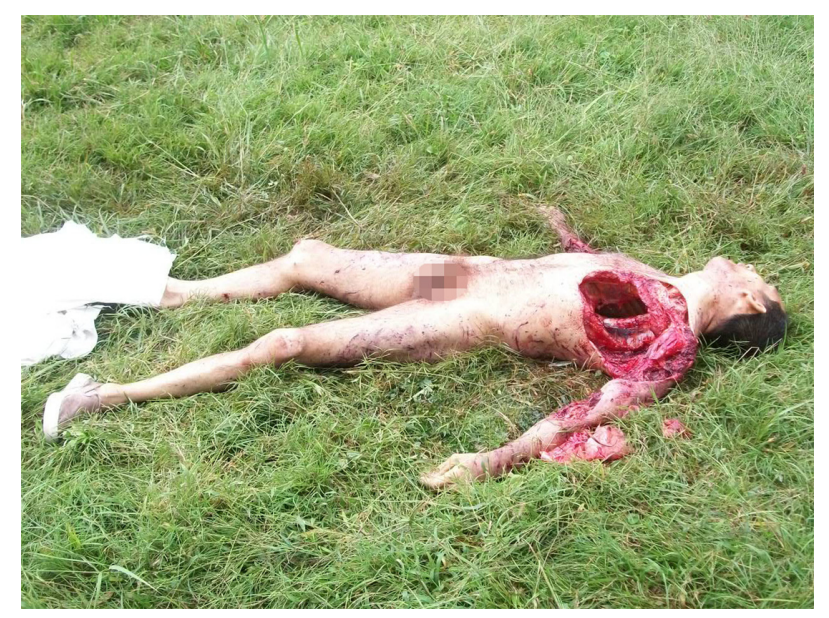

Figure 5 Fatal attack on a mentally disabled 43-year-old man.

Notes: A forensic odontologist and a carnivore biologist established categorically the diagnosis of a dog pack attack when the initial hypothesis of predation either by a very large dog or a cougar was made by the local authorities. The cause of death was attributed to exsanguination due to the extensive injuries. At the scene, a pack of mixed-breed dogs of various sizes was identified later. Image courtesy of Rocio Palacios, BSB, PhD(c), Andean Cat Alliance and of the Laboratory of Forensic Dentistry, Cordoba, Argentina. may be sustained that resemble postmortem depredation: decapitation and defleshing of the face and head of children by animals occurring during life are often witnessed and are usually associated with significant hemorrhage. ${ }^{4,34}$ Although postmortem injuries caused by animals do not show a vital reaction and tend to have yellow-reddened, dried limits, trauma to congested dependent areas may show considerable hemorrhage from postmortem oozing. ${ }^{10}$

We concur with the literature in that histopathological diagnoses serve to reconstruct the event and provide additional information helpful in the overall evaluation in such cases. ${ }^{16,23,35}$ Koszyca et al ${ }^{34}$ demonstrated the value of taking tissues damaged by animal bites during autopsy for histological assessment, as this may be a crucial step in determining the timing of the injuries, and in helping to elucidate the chronology of the fatal event. If a histological vital reaction is detected, it can be assumed that the victim was alive for some time in an incapacitated state prior to death and that death did not occur rapidly. ${ }^{34}$ Salem et al reported a case of an epileptic 27-year-old woman found dead in her home. ${ }^{3}$ The victim had extensive lesions on her neck produced by her mixed-breed dog. Difficulties consisted in determining whether the injuries occurred before or after death; even though self-defense injuries were not present, the histological analyses revealed hemorrhagic reactions in the cutaneous, subcutaneous, and muscle tissue confirming the vitality of the lesions. The authors concluded that the dog's attack probably occurred during the postcritical phase of an epileptic seizure when the victim was unconscious. The odontological examination of bite marks and DNA analysis allowed identifying the dog as the perpetrator. ${ }^{3}$

\section{Motivation}

While a dog bite mark has been conceptualized as "any break in the skin caused by a dog's teeth, regardless of the intention", "the reason of biting" is the Holy Grail when researchers try to explain dog bites from an ethological point of view. ${ }^{30}$ It is clear that the patterns of behavior must be conveniently discriminated according to whether or not they are responsible for the death of the victim. There are quite a few reports where the animal has been involved only indirectly in deaths. In 1992, Opeskin and Lee reported a case of a man who died from blunt throat trauma consistent with infliction by the head of a Greyhound dog. ${ }^{36}$ The key was the identification of an unprovoked and aggressive attitude toward the victim, and the resulting attack with fatal consequences. But the media seems to be indifferent (and certainly negligent) on this point. In 2011 in Chile, 
a headline of a local newspaper read: "the prosecution investigating death of man after attack of a pit bull dog", with a photograph of a Pit Bull Terrier illustrating the report. However, the real circumstances were quite different as the attacking dog (in fact, never confirmed as a pit bull) actually attacked the victim's pet (an Irish Setter), and the owner suffered a sudden cardiac death while trying to separate them. The report was inserted between other related news such as "An elderly woman is wounded after attack of her dogs"; "One girl was killed when being attacked by a dog"; and "A subject dies after being attacked by dogs". ${ }^{37}$ Similar situations can be seen in cases of postmortem depredation. Domestic dogs are recognized but unappreciated scavengers; ${ }^{38}$ when an individual dies from natural (or not animal dependent) causes, he or she becomes part of the ecological cycle and the animal may simply view the body as a source of nutrition leading to postmortem depredation with obvious but grotesque changes and mutilations. ${ }^{20}$ This apparently simple assertion may not be sufficiently interpreted by the authorities, and the dog is unjustifiably destroyed (Figure 2). The abovementioned is contradictory of the current trends to prevent animal cruelty, abuse, and neglect. ${ }^{39}$ Conversely, but along the same thin line, several countries have reported an increase in the number of attacks by packs of feral dogs not only on humans but also on livestock in the last few years. ${ }^{16,17,40,41}$ Some of these countries have also attempted to enact laws to prevent this hazard. On January 31, 2015, Chile permitted in its Hunting Regulations, the hunt of "[...] wild or feral dogs, which are in packs, outside of the urban areas, at a distance of $>400 \mathrm{~m}$ away from any village or rural housing isolated, which must be caught or hunted in the terms set forth in this Act and regulation". ${ }^{42}$ Almost 120 Chilean animal defense leagues pointed out that the capture and hunt of dogs would imply the nondiscrimination of hunted animals and would represent an incentive for the abandonment of dogs outside of urban areas. These organizations argued that the Rule was irregularly processed and that the normative distorts the draft law of Responsible Ownership of Companion Animals or Pets. From the other side, and in a public statement, the Faculty of Veterinary and Animal Sciences of the University of Chile stated that feral dogs have become a serious environmental problem that affects various wild animals. The academics also emphasize that because of their status as feral, it is very unlikely that adoption campaigns allow the effective integration of these animals to the homes, and they adhered to the rule. Due to the protests of these groups and to the controversy generated in the public opinion, the rule was finally abolished 15 days later. ${ }^{43}$

Regardless of any subjective appreciation, hunger is reasonably the first motivation explained when dealing with dog scavenging; however, this hypothesis cannot explain the mutilation patterns where the postmortem interval was too short for starvation, dogs had access to food, or the injury pattern cannot be explained as an initial feeding behavior. ${ }^{12,30}$ Rothschild and Schneider (1997) ${ }^{30}$ present a case in which a well-behaved pet dog (an Alsatian) with no motivation of hunger started to mutilate the body of its owner within the first 45 minutes after death. In fact, shortly after the body was discovered, the dog vomited a large quantity of commercial dog food in addition to human tissue, which indicates that the dog was not hungry at the time of mutilation. The authors provide a possible explanation in which the pet tried to help him first by licking or nudging, but when this failed to produce any results, the behavior of the animal became confused and feared leading to biting. ${ }^{30}$ This "displacement behavior" of animals trying to revive their owners and the shift in the human-dog hierarchy (explained by the unusual mutilations - emasculation or decapitation) are reasonable theories supported by some reported cases. ${ }^{12,25}$

When the dog is directly responsible for the death, the considerations are quite different. Man has been transformed into prey, and the animal into hunter, and several factors have been described as contributors of this atavistic relationship. Borchelt et al examined most of the animals that participated in two fatal attacks and observed them under conditions simulating those that may have elicited or contributed to the maulings. ${ }^{5}$ Among the different roles analyzed by the authors, the following are remarkable: 1) the "role of hunger" cannot explain all patterns of dog pack attacks; 2) once the attack has been initiated, previous histories of social facilitation of feeding could have facilitated predatory behavior by the entire pack; 3) invasion of territory can lead wild and domestic canids to attack; 4) even though the majority of dogs were extremely variable in their behavior toward strangers, all the animals had unsupervised activity and aggressive social interactions with people; 5) the presence of an estrus female can lead to aggressive competition among male dogs; and 6) the visual stimulus of moving prey seems to be one of the main triggers of attack behavior. The flailing of arms, rapid movements, or attempts at self-defense by the victim can increase the intensity of the attacks (in fact, moving slowly or not moving at all can result in a reduction of this intensity). ${ }^{5}$ It has been mentioned that 
in a pack situation, once an aggressive act is initiated, whether as a playful nip or a serious bite, dogs which singly taken are docile, may join and the pack instinct escalates the attack until the victim is killed or the dogs are driven off. ${ }^{6}$

We agree with Borchelt et al that the use of behavioral analysis and simulation methods to evaluate the possible factors in dog attacks can instill confidence in the observations when there is some doubt as to the cause of death in unwitnessed cases. These observations can provide some insight into the warning signs of dog attacks. ${ }^{5}$

\section{Strategies for prevention and risk mitigation}

Severe dog attacks are a probable product of many factors not only animal related but also victim related. ${ }^{2,5,14}$ A public health program that aimed at reducing these incidents could be directed to both of them, but the major strategy has been the promotion of a breed-specific legislation (BSL). ${ }^{1,13,44,45}$ BSL typically prohibits the breeding and ownership of certain breeds or types of dogs categorized as "dangerous" or "aggressive", which is based on attack records or aggressive potential. ${ }^{46}$ However, any dog can be prepared for attack and a precise determination of breed may not be posible. ${ }^{8,13}$ Obtaining a honest attack record is difficult due to scarce data on the reference population, incomplete breed registration, incorrect breed identification, the number of nonpurebred dogs, and the narrow scope of relevant studies. ${ }^{6,14,46}$ Moreover, while BSL is rarely based on such records ${ }^{46}$ periodically there are reports of other breeds responsible for maulings and deaths. ${ }^{4}$ Saint Bernard, Great Dane, Golden Retriever, Collie, Labrador Retriever, Dachshund, and Yorkshire Terrier are not aggressive breeds, but they have mauled persons to death on occasion..$^{14}$ Great Danes caused the most reported human dog bite-related fatalities between 1997 and 1998 in the United States, and since 1975, dogs belonging to $>30$ breeds have been responsible for fatal attacks on people. ${ }^{14}$ Cornelissen and Hopster affirmed that all dogs can bite and therefore one should always be careful when interacting with a dog, even a family dog and during play. The authors "found that the Jack Russell terrier was responsible for approximately $10 \%$ of bites, and $8 / 10$ of the most popular breeds were the most common biters (including the highly polymorphic group of mixed breed/mongrel)" ${ }^{46}$ Furthermore, the necessary objective methods of determining the breed of the involved dog (pedigree analysis and DNA testing) are potentially time consuming, expensive, and mostly complicated efforts. ${ }^{14}$ Inconsistencies are not unusual. Although the German Shepherd has been associated frequently with fatal attacks, ${ }^{15,44}$ this breed is not considered as dangerous by some legislation, ${ }^{45}$ and it is used by both the army and the police or as a guard dog. ${ }^{44}$ This is not a minor point; police dogs are trained to bite with strength, using the entire mouth (including their whole set of teeth), resulting in more serious wounds. Fighting dogs are trained to attack other dogs and not people, unlike police dogs. ${ }^{44}$ Similarities between banned types and other dog breeds such as the Pit Bull and the Staffordshire Bull Terriers are apparent, and experts are needed for correct identification. Thus, the potential for wrongly identifying a dog may result in a dog being held within kennels for long periods or a breed/type being overrepresented in incident reports. ${ }^{44}$ BSLs do not address the fact that a dog of any breed can become dangerous when bred or trained to be aggressive. ${ }^{14} \mathrm{~A}$ change in the current regulations would prevent dogs that are not dangerous but may belong to a specific breed/type from spending long periods in kennels. ${ }^{44}$ An alternative to BSL is to regulate individual dogs and owners on the basis of their behavior. ${ }^{14}$ Most of the responsibility for such attacks lies with the dog owner. ${ }^{7}$ In terms of some legislatures, "a person who keeps or controls an animal in his own interest is liable "without fault' because he/she creates an increased risk of harm to the community" ${ }^{8}$ Generic nonbreed-specific dangerous dog laws can be enacted that place primary responsibility for a dog's behavior on the owner, regardless of the dog's breed. If dog owners are required to assume legal liability for the behavior and actions of their pets, they may be encouraged to seek professional help in training and socializing their pets. ${ }^{14}$

Dog bite mark analysis should be consistent with a multidisciplinary plan of action involving different forensic experts as pathologists, odontologists, veterinarians, biologists, crime investigators, and others. ${ }^{8}$ The scientific inclusion/exclusion of the dog involved, regardless of the final destination of the animal, must be one of the explicit goals of the forensic approach in these cases because of the possible serious criminal, legal, and/or financial consequences for the owners of the animal. ${ }^{19,31}$ De Munnynck and Van de Voorde underlined that if dog bites are to be prevented, it is necessary to comprehend not only the particular conditions but also the behavior of both victim and dog. ${ }^{2}$ It is imperative to recognize that companion animals require to understand appropriately this relationship as "a complex subject". ${ }^{32}$ Programs should strive to ensure that dogs receive proper socialization, exercise, and attention; that they are 
given adequate food, water, shelter, and veterinary care; that they are neutered if they are not maintained for legitimate and responsible breeding purposes; and that they are trained humanely and confined safely. ${ }^{14}$

\section{Conclusion}

- An appropriate forensic approach must include detailed assessment of the scene, the victim, and the animals involved.

- Dog bite mark analysis should be consistent with a multidisciplinary plan of action involving different forensic experts as pathologists, odontologists, veterinarians, biologists, crime investigators, and others.

- A scientific inclusion/exclusion of the dog involved is possible and also recommended because of the possible serious criminal, legal, and/or financial consequences for the owner of the animal.

- Prevention strategies should be addressed to both dog owners and people who do not own a dog by educating about how to deal with dogs, dog behavior, and "dog language".

\section{Acknowledgment}

We are especially thankful to P James Macaluso Jr, PhD, for his help and valuable suggestions during preparation of the manuscript. Funding was provided by Attraction and Insertion of Advanced Human Capital Program, MEC 80140078 Conicyt, Chile. The authors had ethical permission to use all photographs included in this paper.

\section{Disclosure}

The authors report no conflicts of interest in this work.

\section{References}

1. Souviron RR. Animal bites. In: Dorion RBJ, editor. Bitemark Evidence: A Color Atlas and Text. 2nd ed. Boca Raton: CRC Press; 2011:209-216.

2. De Munnynck K, Van de Voorde W. Forensic approach of fatal dog attacks: a case report and literature review. Int J Legal Med. 2002;116(5): 295-300.

3. Salem NH, Belhadj M, Aissaoui A, Mesrati MA, Chadly A. Multidisciplinary approach to fatal dog attacks: a forensic case study. J Forensic Leg Med. 2013;20(6):763-766.

4. Dorion RBJ. Carnivore bitemarks. In: Dorion RBJ, editor. Bitemark Evidence: A Color Atlas and Text. 2nd ed. Boca Raton: CRC Press; 2011:217-240.

5. Borchelt PL, Lockwood R, Beck AM, Voith VL. Attacks by packs of dogs involving predation on human beings. Public Health Rep. 1983;98(1): 57-66.

6. Pomara C, D’Errico S, Jarussi V, Turillazzi E, Fineschi V. Cave canem: bite mark analysis in a fatal dog pack attack. Am J Forensic Med Pathol. 2011;32(1):50-54.

7. Kneafsey B, Condon KC. Severe dog-bite injuries, introducing the concept of pack attack: a literature review and seven case reports. Injury. 1995;26(1):37-41.
8. Bernitz H, Bernitz Z, Steenkamp G, Blumenthal R, Stols G. The individualisation of a dog bite mark: a case study highlighting the bite mark analysis, with emphasis on differences between dog and human bite marks. Int J Legal Med. 2012;126(3):441-446.

9. Bernstein ML. The nature of bitemarks. In: Dorion RBJ, editor. Bitemark Evidence: A Color Atlas and Text. 2nd ed. Boca Raton: CRC Press; 2011:53-56.

10. Byard RW, James RA, Gilbert JD. Diagnostic problems associated with cadaveric trauma from animal activity. Am J Forensic Med Pathol. 2002;23(3):238-244.

11. Agnarsson I, Kuntner M, May-Collado LJ. Dogs, cats, and kin: a molecular species-level phylogeny of carnivora. Mol Phylogenet Evol. 2010;54(3):726-745.

12. Colard T, Delannoy Y, Naji S, Gosset D, Hartnett K, Bécart A. Specific patterns of canine scavenging in indoor settings. J Forensic Sci. 2015;60(2):495-500.

13. Tsokos M, Byard RW, Püschel K. Extensive and mutilating craniofacial trauma involving defleshing and decapitation: unusual features of fatal dog attacks in the young. Am J Forensic Med Pathol. 2007;28(2):131-136.

14. Sacks JJ, Sinclair L, Gilchrist J, Golab GC, Lockwood R. Breeds of dogs involved in fatal human attacks in the United States between 1979 and 1998. J Am Vet Med Assoc. 2000;217(6):836-840.

15. Jarrett P. Which dogs bite? Arch Emerg Med. 1991;8(1):33-35.

16. Santoro V, Smaldone G, Lozito P, Smaldone M, Introna F. A forensic approach to fatal dog attacks. A case study and review of the literature. Forensic Sci Int. 2011;206(1-3):e37-e42.

17. Fonseca GM, Palacios R. An unusual case of predation: dog pack or cougar attack? J Forensic Sci. 2013;58(1):224-227.

18. Kalinkat G. Bringing animal personality research into the food web arena. J Anim Ecol. 2014;83(6):1245-1247.

19. Tokdemir MB, Çetin G, Şam B, Özer E, Yıldırım A, Bütün C. The challenges in autopsy cases exposed to animal attack. Med Sci. 2014;3(2):1209-1223.

20. Fegan-Earl A. Animal attack injuries: fatal and non fatal. In: Payne-James J, Byard R, Corey T, Henderson C, editors. Encyclopedia of Forensic and Legal Medicine 1. Oxford: Academic Press. 2005:68-71.

21. Haglund WD, Reay DT, Swindler DR. Canid scavenging/disarticulation sequence of human remains in the Pacific Northwest. J Forensic Sci. 1989;34(3):587-606.

22. Kiuchi T, Matoba K, Terazawa K. Unusual injuries on the right hand and forearm caused by unidentified wild animals. Leg Med (Tokyo). 2008;10(6):301-305.

23. Verzeletti A, Cortellini V, Vassalini M. Post-mortem injuries by a dog: a case report. J Forensic Leg Med. 2010;17(4):216-219.

24. Rabinovich R, Kahana T. Animal attacks and injuries: predation. In: Payne-James J, Byard R, Corey T, Henderson C, editors. Encyclopedia of Forensic and Legal Medicine 1. Oxford: Academic Press; 2005: 71-79.

25. Steadman DW, Worne H. Canine scavenging of human remains in an indoor setting. Forensic Sci Int. 2007;173(1):78-82.

26. Byard RW. Animals, autopsies and artefacts. Forensic Sci Med Pathol. 2011;7(4):309-310.

27. Stiegler D, Gilbert JD, Warner MS, Byard RW. Fatal dog bite in the absence of significant trauma: Capnocytophaga canimorsus infection and unexpected death. Am J Forensic Med Pathol. 2010;31(2): 198-199.

28. Gunn A. Essential Forensic Biology. 2nd ed. Singapore: WileyBlackwell; 2009.

29. Byard RW, Tsokos M. Forensic issues in cases of diogenes syndrome. Am J Forensic Med Pathol. 2007;28(2):177-181.

30. Rothschild MA, Schneider V. On the temporal onset of postmortem animal scavenging. "Motivation" of the animal. Forensic Sci Int. 1997; 89(1-2):57-64.

31. Brauner P, Reshef A, Gorski A. DNA profiling of trace evidence mitigating evidence in a dog biting case. J Forensic Sci. 2001;46(5): 1232-1234 
32. Murmann DC, Brumit PC, Schrader BA, Senn DR. A comparison of animal jaws and bite mark patterns. J Forensic Sci. 2006;51(4): 846-860.

33. Stols G, Bernitz H. Reconstruction of deformed bite marks using affine transformations. J Forensic Sci. 2010;55(3):784-787.

34. Koszyca B, Gilbert JD, Byard RW. Antemortem trauma from rodent activity the popiel phenomenon. Forensic Sci Med Pathol. 2006;2(4):269-272.

35. Dettmeyer RB. The role of histopathology in forensic practice: an overview. Forensic Sci Med Pathol. 2014;10(3):401-412.

36. Opeskin K, Lee KA. Death by greyhound. Forensic Sci Int. 1992;56(1): 51-57.

37. Cooperativa.cl. Fiscalia investiga muerte de hombre tras ataque de perro pitbull en Pitrufquén [The prosecution investigating death of man after attack of a pit bull dog in Pitrufquen]. Radio Cooperativa; 2011 [published on the Internet]. Available from: http://www.cooperativa. $\mathrm{cl} /$ noticias/pais/policial/ataques-de-perros/fiscalia-investiga-muertede-hombre-tras-ataque-de-perro-pitbull-en-pitrufquen/2011-0420/163101.html. Accessed July 7, 2015. Spanish.

38. Beck J, Ostericher I, Sollish G, De Leon J. Animal scavenging and scattering and the implications for documenting the deaths of undocumented border crossers in the Sonoran Desert. J Forensic Sci. 2015;60(Suppl 1):S11-S20.

39. Gerdin JA, McDonough SP. Forensic pathology of companion animal abuse and neglect. Vet Pathol. 2013;50(6):994-1006.

40. Forrester JA, Holstege CP, Forrester JD. Fatalities from venomous and nonvenomous animals in the United States (1999-2007). Wilderness Environ Med. 2012;23(2):146-152.
41. Clarke M, Vandenberg N. Dog attack: the application of canine DNA profiling in forensic casework. Forensic Sci Med Pathol. 2010;6(3): $151-157$.

42. Ministry of Agriculture. Rule No 65, published on January 31th of 2015. Approved amendment for the regulation of the Hunting Law, adopted by Rule No 5, 1998. Art. 6. Available from: http://www.leychile.cl. Accessed July 7, 2015.

43. Fundación Casa de la Paz [homepage on the Internet]. Ley de caza de perros asilvestrados: ¿problema ecológico o matanza injustificada? [Hunting Law of feral dogs: ecological problem or unjustified killing?] Available from: http://acuerdos.cl/debates/ley-de-caza-de-perrosasilvestrados-problema-ecologico-o-matanza-injustificada/. Accessed July 7, 2015. Spanish.

44. Oxley JA, Farr KJ, De Luna CJ. Dog owners' perceptions of breed-specific dangerous dog legislation in the UK. Vet Rec. 2012; 171(17):424.

45. Ministry of the Presidency, Government of Spain. Royal Decree $287 / 2002$, of 22 March, by which develops the Law 50/1999, of December 23, on the legal regime of possession of potentially dangerous wild animals. Off Bull State. 2002;74:12290-12292. Available from: http://www.boe.es/buscar/doc.php?id=BOE-A-20026016. Accessed July 7, 2015.

46. Cornelissen JM, Hopster H. Dog bites in The Netherlands: a study of victims, injuries, circumstances and aggressors to support evaluation of breed specific legislation. Vet J. 2010;186(3):292-298.
Research and Reports in Forensic Medical Science

\section{Publish your work in this journal}

Research and Reports in Forensic Medical Science is an international, peer-reviewed, open access journal publishing original research, reports, reviews and commentaries on all areas of forensic medical science. The manuscript management system is completely online and includes a

\section{Dovepress}

very quick and fair peer-review system. Visit http://www.dovepress.com/ testimonials.php to read real quotes from published authors. 